We try to publish authors' responses in the same edition with readers' comments. Time constraints might prevent this in some cases. The problem is compounded in a bimonthly journal where continuity of comment and redress are difficult to achieve. When the redress appears 2 months after the comment, 4 months will have passed since the article was published. Therefore, we would suggest to our readers that their correspondence about published papers be submitted as soon as possible after the article appears.

\section{Critical Appraisal of the Literature}

To the Editor: Dr. Miser provides a valuable service with his article on the basics of critical appraisal of the medical literature. ${ }^{1}$ I would suggest, however, an important step to be taken at the beginning of the process: composing a focused, answerable clinical question. Neglecting to do so can lead one astray, and Dr. Miser's case 2 is a good example. In this case, the hypothetical physician was not in the habit of using corticosteroids to treat outpatients with croup but was beginning to wonder whether to start doing so. The clinical question, then, was, "Are corticosteroids superior to the cool humidified air that I currently use to treat children with croup?" In other words, "Should I change my current practices in the treatment of croup?"

Once this question is stated explicitly, it becomes quickly obvious that the article in question cannot, by its design, provide an answer. The article by Klassen et al is a randomized controlled trial of three treatments for croup: oral dexamethasone, nebulized budesonide, or both. ${ }^{2}$ The trial does not include as one of its arms the treatment that our hypothetical physician is currently using, ie, cool mist only. This article, therefore, while perhaps helpful in answering certain questions, cannot provide any useful information to help answer the question at hand. The article could be disposed of within 2 minutes, thereby liberating the physician to peruse other, more relevant articles.

The methods reviewed by Dr. Miser can be very useful. We should take care, however, to make sure that we are applying them to the right question.

Christopher W. Ryan, MD

United Health Services Johnson City, NY

\section{References}

1. Miser WF. Critical appraisal of the literature. J Am Board Fam Pract 1999;12:315-33.

2. Klassen TP, Craig WR, Moher D, et al. Nebulized budesonide and oral dexamethasone for treatment of croup: a randomized controlled trial. JAMA 1998;279:1629-32.

\section{Firearm Safety as Preventive Medicine}

To the Editor: It was interesting to note that Shaughnessy and colleagues seemed to be surprised when patients were unimpressed by physician's exhortation about gun safety (Shaugnessy et al. Family practice patients' attitudes toward firearm safety as a preventive medicine issue: a HARTNET study. J Am Board Fam Pract 1999; 12:354-9). Their attitude is in response to their experience. Politically correct "cooked" statistics not withstanding, people know that firearms are highly useful in repelling violence and pose only a minute threat to the vast majority. Negligent and accidental discharges and intentional shootings occur in a small subset of the population, a group apparently beyond being influenced by most authority figures.

\section{Kenneth E. Wagner, MD} Carpinteria, Calif

\section{Birth and Death Through a Child's Eyes}

To the Editor: Please accept my congratulations on the publishing of Dr. Elizabeth Feldman's "Birth and Death: Through a Child's Eyes" as a Reflections in Family Practice article (J Am Board Fam Pract 1999;12:344-5). This short piece touched me deeply. It addressed important issues in family practice - how the family integrates these important life events into the lives of children, and how it can be done in a natural, caring, family-centered way. I have used it severeal times since its appearance in my teaching of both residents and medical students with universally positive responses. In addition to the issues it addresses, it reminds me that physicians have families, too, and experience all the stages of the family life cycle. I greatly appreciate Dr. Feldman's willingness to help us learn through sharing her personal experiences with us.

Joshua Freeman, MD

Department of Family Practice University of Texas Health Science Center San Antonio

To the Editor: What a pleasure and honor to have opened $\mathcal{F} A B F P$ and read the intensely beautiful piece "Birth and Death: Through a Child's Eyes," by Elizabeth Feldman (J Am Board Fam Pract 1999;12:344-5). It was touching, candid, intensely personal, and beautifully written.

I feel honored to know the author and her family, Jay, Hannah, and Leah. I remember the videotape that Jay produced for the Public Broadcasting System about Dr. Feldman's father and others at the end of their lives.

I like the ease with which the author writes about Jewish life events, including the Sabbath.

Reading this piece this morning started my week on a serene and beautiful note.

Paul Gordon, MD

Department of Family \& Community Medicine University of Arizona College of Medicine

Tucson 